\title{
Influencing Factors of Real Estate Price based on Grey Relational Analysis
}

\author{
Lei Jiang and Yunli Gao*
}

School of Civil Engineering and Architecture, Dalian Nationalities University, Dalian, Liaoning, 116600, China

\begin{abstract}
This research answers the question of how to measure the impact of different factors on real estate price. It is well known that the real estate price is influenced by many factors, however, how to determine the factors and evaluate the influence degree is an important problem. Most of the previous research used multivariate statistical model, this paper proposed a different way-Grey Relational Analysis (GRA). This paper selected 11 influencing factors from economic area, market area, cost area and social area. Then the method to identify the influence degree of factors based on GRA was proposed. In addition, for explaining application of the influencing factors, the case of Dalian in China is studied. The result is that the key influencing factors are gross domestic product, average wage of employed persons in construction, annual per capita disposable income of urban households and per capita building space of urban household. The GRA is an effective way to assess the impact of different factors on real estate price and provides a good tool for designers, users, decision makers and researchers.
\end{abstract}

Keywords: Grey relational analysis (GRA), influencing factor, real estate price.

\section{INTRODUCTION}

Real estate is a key factor in national economics. The real estate price is influenced by many different factors, which is a well known and more studied subject in literature. Researchers has studied the influencing factors from different aspects, such as national and regional macroeconomic factors [1], real estate sub-markets [2], environment quality on residentia location [3], policy actions [4] and population changes [5] Scholars often use multivariate statistical model to study the economic, which cannot explain the dynamic behaviors of economic [6].

Grey theory, which was proposed by J.L. Deng, is one of the new mathematical theories widely applied in various fields of science. Grey theory has advantages in the fields of uncertainty fields, and it is an effective method used to solve uncertainty problems with discrete data and incomplete information. Grey relational analysis [7] drived form grey systems theory is a measurement method to determine the relationship between sequences using limited amounts of data. Grey Relational Analysis (GRA) is suitable for solving problems with complicated interrelationships between multiple factors and variables [8], which has been widely applied to various field. For example, GRA was used to find out the relative importance of 4 different kinds energy consumption and economic growth [9]. A general sustainability indicator of renewable energy system is proposed to measure the sustainability of a renewable systems through GRA [10]. The "four elements and two hierarchies" model for advantages transformation are established and the methods to identify the key transformation factors are used by GRA [11]. A self-adaptation evaluation method in real time dynamics decision-making system is suggested based on grey close relationship [12]. About inter-enterprise cooperation and innovation in industrial clusters, a novel knowledge similarity degree based on GRA is proposed, and a dynamic evolution model of innovation net work is proposed [13].

This paper selected 11 different influencing factors of the real estate price, then a model based on GRA is established. After that, a case study of Dalian in China is applied, and the result and conclusion is summarized.

\section{SLECTION OF FACTORS}

This paper focuses on the real estate price and the influencing factors of it, by studying the literature and investigation, this paper has chosen 11 factors in 4 different areas, which are economic area, market area, cost area and social area, as shown in Table $\mathbf{1 .}$

\section{INFLUENCING MODEL BASED ON GRA}

To model the influencing factors of real estate, the first step is normalize all the factors and real estate price on the interval $[0,1]$. Then, the grey relational coefficients are calculated. After that, the grey relational grades are computed. The final procedure is to order the factors and analysis the evaluation results.

\subsection{Normalization of the Original Values}

The original sequences which have different dimensions and magnitudes couldn't be compared directly, so they should be converted to a comparable sequence which is generally dimensionless.

The algorithm of GRA is defined as follows.

Let the original reference sequence is

$$
X_{0}=\left(x_{0}(1) \epsilon_{-}(2) \in \neg f-x_{0}(n)\right)
$$


Table 1. The criteria of influencing factors.

\begin{tabular}{|c|c|c|c|}
\hline Areas & Factors & Mean of Factors & Unit \\
\hline \multirow{3}{*}{ Economic } & $\mathrm{X} 1$ & gross domestic product & hundred million yuan \\
\hline & $\mathrm{X} 2$ & annual per capita disposable income of urban households & yuan \\
\hline & $\mathrm{X} 3$ & annual per capita consumption expenditure of urban households & yuan \\
\hline \multirow{3}{*}{ Market } & $\mathrm{X} 4$ & real estate investment complete this year & thousand yuan \\
\hline & $\mathrm{X} 5$ & floor space of commercialized building sold & $\mathrm{m}^{2}$ \\
\hline & $\mathrm{X} 6$ & floor space complete & $\mathrm{m}^{2}$ \\
\hline \multirow{3}{*}{ Cost } & $\mathrm{X} 7$ & average price of land purchased & yuan \\
\hline & $\mathrm{X} 8$ & purchasing price index for building materials & -- \\
\hline & $\mathrm{X} 9$ & average wage of employed persons in construction & yuan \\
\hline \multirow{2}{*}{ Social } & $\mathrm{X} 10$ & total population of a country or region & thousand people \\
\hline & $\mathrm{X} 11$ & per capita building space of urban household & $\mathrm{m}^{2}$ \\
\hline
\end{tabular}

Let the sequences for comparison are

$$
\begin{aligned}
& X_{1}=\left(\begin{array}{lll}
x_{1}(1) & x_{1}(2) \cdots & x_{1}(n)
\end{array}\right) \\
& X_{2}=\left(\begin{array}{llll}
x_{2}(1) & x_{2}(2) \cdots & x_{2}(n)
\end{array}\right) \\
& \cdots \cdots \cdots \cdots \\
& X_{m}=\left(\begin{array}{llll}
x_{m}(1) & x_{m}(2) \cdots & x_{m}(n)
\end{array}\right)
\end{aligned}
$$

There are three different normalization methods for different situations:

for the greater the better situation, the normalization is:

$$
x_{i}^{\prime}(k)=\frac{x_{i}(k)-\min x_{i}(k)}{\max _{i} x_{i}(k)-\min _{i} x_{i}(k)}
$$

for the smaller the better situation, the normalization is:

$$
x_{i}^{\prime}(k)=\frac{\max _{i}(k)-x_{i}(k)}{\max _{i} x_{i}(k)-\min _{i} x_{i}(k)}
$$

for the ideal value which is represented as $\mathrm{x} 0$ is the better situation, the normalization is:

$$
x_{i}^{\prime}(k)=1-\frac{\left|x_{i}(k)-x^{0}\right|}{\underset{i}{\max \left|x_{i}(k)-x^{0}\right|}}
$$

\subsection{Calculation of the Grey Relational Coefficients}

The grey relational coefficient between the normalized comparative sequence $\mathrm{Xi}$ and the reference sequence $\mathrm{X} 0$ is defined as:

$$
\xi_{0 i}(j)=\frac{\min _{i} \min _{j} z_{i j}+\rho \max _{i} \max _{j} z_{i j}}{z_{i j}+\max _{i} \max _{j} z_{i j}}, i \in m ; j \in n
$$

where is deviation between $\mathrm{X} 0$ and $\mathrm{Xi}$ : $z_{i j}=\left|x_{0 j}-x_{i j}\right|$

$\rho$ is the distinguishing coefficient, $\rho_{\in(0,1) \text {, usually, }}$ $\rho=0.5$.

\subsection{Calculation of the Comprehensive Coefficient}

The grey relational grade for the sequence of $\mathrm{Xi}$ is calculated by averaging the grey relational coefficients as follows:

$r_{i}=\frac{1}{n} \sum_{j=1}^{m} \xi_{0 i}(j), i \in m$

The grey relational grade $\gamma \mathrm{i}$ defines the effect of comparative sequence to the tendency of reference sequence, and the comparative sequence are ordered by it.

\section{CASE STYDY}

In this study, we used GRA in order to find out the importance of influence factors on real estate price for Dalian in China. We defined that the average selling price of commercialized buildings as X0, and the unit of it is yuan $/ \mathrm{m}^{2}$. We used 2007-2012 data as shown in Table 2 for calculations to compute the GRA between real estate price and the influencing factors. By racking the factors, we try to show the influence degree of different factors and which are the important factors influencing real estate price for Dalian.

At first we normalized the original sequences and attained the values in the Table 3 . We used the greater the better for all the sequences.

Then we calculated the grey relational coefficients, in the last step of calculations we computed grey relational grades by averaging the grey relational coefficients for each comparative sequence. Grey relational coefficients and grey relational grades as well as rankings of them are shown in Table 4. 
Table 2. Values used in the analysis.

\begin{tabular}{|c|c|c|c|c|c|c|}
\hline Values & 2007 & 2008 & 2009 & 2010 & 2011 & 2012 \\
\hline $\mathrm{X} 0$ & 5567.76 & 5774.26 & 6249.04 & 7043.68 & 8052.00 & 8003.99 \\
\hline $\mathrm{X} 1$ & 3078.80 & 3803.30 & 4349.50 & 5158.20 & 6150.60 & 7002.80 \\
\hline $\mathrm{X} 2$ & 15108.60 & 17500.48 & 19014.37 & 21292.56 & 24276.16 & 27539.2 \\
\hline $\mathrm{X} 3$ & 12135.00 & 14101.38 & 15329.83 & 16579.70 & 18846.40 & 20417.46 \\
\hline $\mathrm{X} 4$ & 40357020 & 49581600 & 57894210 & 76802020 & 110746300 & 139652040 \\
\hline $\mathrm{X} 5$ & 8282375 & 8227065 & 11526834 & 12153259 & 9099105 & 10763024 \\
\hline $\mathrm{X} 6$ & 4283064 & 7555621 & 5496520 & 5709735 & 9428724 & 7499976 \\
\hline $\mathrm{X} 7$ & 1190.46 & 2288.23 & 2007.28 & 2020.71 & 1871.72 & 2540.97 \\
\hline $\mathrm{X} 8$ & 94.60 & 107.10 & 97.50 & 106.41 & 110.17 & 101.11 \\
\hline X9 & 25504.20 & 27333.27 & 35027.61 & 41601.58 & 43714.00 & 45099 \\
\hline $\mathrm{X} 10$ & 5782 & 5833 & 5848 & 5864 & 5885 & 5903 \\
\hline X11 & 24.64 & 24.07 & 25.04 & 25.67 & 27.04 & 27.3 \\
\hline
\end{tabular}

Table 3. Normalized values.

\begin{tabular}{|c|c|c|c|c|c|c|}
\hline Factors & 2007 & 2008 & 2009 & 2010 & 2011 & 2012 \\
\hline X0 & 0.0000 & 0.0831 & 0.2742 & 0.5941 & 1.0000 & 0.9807 \\
\hline $\mathrm{X} 1$ & 0.0000 & 0.1846 & 0.3238 & 0.5299 & 0.7828 & 1.0000 \\
\hline $\mathrm{X} 2$ & 0.0000 & 0.1924 & 0.3142 & 0.4975 & 0.7375 & 1.0000 \\
\hline $\mathrm{X} 3$ & 0.0000 & 0.2374 & 0.3857 & 0.5366 & 0.8103 & 1.0000 \\
\hline $\mathrm{X} 4$ & 0.0000 & 0.0929 & 0.1766 & 0.3670 & 0.7089 & 1.0000 \\
\hline $\mathrm{X} 5$ & 0.0141 & 0.0000 & 0.8404 & 1.0000 & 0.2221 & 0.6459 \\
\hline X6 & 0.0000 & 0.6360 & 0.2358 & 0.2773 & 1.0000 & 0.6252 \\
\hline $\mathrm{X} 7$ & 0.0000 & 0.8129 & 0.6048 & 0.6148 & 0.5044 & 1.0000 \\
\hline $\mathrm{X} 8$ & 0.0000 & 0.8028 & 0.1863 & 0.7585 & 1.0000 & 0.4181 \\
\hline X9 & 0.0000 & 0.0933 & 0.4860 & 0.8215 & 0.9293 & 1.0000 \\
\hline $\mathrm{X} 10$ & 0.0000 & 0.4215 & 0.5455 & 0.6777 & 0.8512 & 1.0000 \\
\hline $\mathrm{X} 11$ & 0.1765 & 0.0000 & 0.3003 & 0.4954 & 0.9195 & 1.0000 \\
\hline
\end{tabular}

\section{RESULTS}

The grey relational coefficients quantify the relationship between the factors and real estate price. The value of the coefficients is higher, the relational degree of the factor with real estate price is higher. The calculated result are shown in Fig. (1).

\subsection{Results of 11 Grey Relational Coefficients}

The factors which are above 0.8 are selected as the key influential factors for real estate price. In this case, there are 6 factors are selected, they are X1 (gross domestic product),
X9(average wage of employed persons in construction), X2(annual per capita disposable income of urban households), X11(per capita building space of urban household), X3(annual per capita consumption expenditure of urban households) and X4(real estate investment complete this year).

The grey relational coefficients of economic factors reflect the influencing degree of economic factors acting on real estate price. The higher the coefficients, the stronger is the impact. As can be seen in Table 4, all the economic factors are in the top 5 factors, which means economic factors have a close relationship with real estate price. Two factors 
Table 4. Grey relational coefficients and grey relational grades.

\begin{tabular}{|c|c|c|c|c|c|c|c|c|c|}
\hline Factors & 2007 & 2008 & 2009 & 2010 & 2011 & 2012 & Mean & Rank & $\begin{array}{c}\text { Mean for } \\
\text { Areas }\end{array}$ \\
\hline $\mathrm{X} 1$ & 1.0000 & 0.7930 & 0.8869 & 0.8583 & 0.6417 & 0.9527 & 0.8554 & 1 & \multirow{3}{*}{0.8422} \\
\hline $\mathrm{X} 2$ & 1.0000 & 0.7806 & 0.9068 & 0.8010 & 0.5970 & 0.9527 & 0.8397 & 3 & \\
\hline $\mathrm{X} 3$ & 1.0000 & 0.7160 & 0.7772 & 0.8713 & 0.6722 & 0.9527 & 0.8315 & 5 & \\
\hline $\mathrm{X} 5$ & 0.9650 & 0.8239 & 0.4072 & 0.4893 & 0.3333 & 0.5374 & 0.5927 & 11 & \multirow[t]{2}{*}{0.7158} \\
\hline X6 & 1.0000 & 0.4130 & 0.9101 & 0.5511 & 1.0000 & 0.5225 & 0.7328 & 8 & \\
\hline $\mathrm{X} 7$ & 1.0000 & 0.3477 & 0.5406 & 0.9496 & 0.4397 & 0.9527 & 0.7050 & 10 & \multirow[b]{2}{*}{0.7533} \\
\hline $\mathrm{X} 8$ & 1.0000 & 0.3508 & 0.8155 & 0.7029 & 1.0000 & 0.4088 & 0.7130 & 9 & \\
\hline $\mathrm{X} 11$ & 0.6879 & 0.8239 & 0.9372 & 0.7975 & 0.8285 & 0.9527 & 0.8379 & 4 & 0.8042 \\
\hline
\end{tabular}

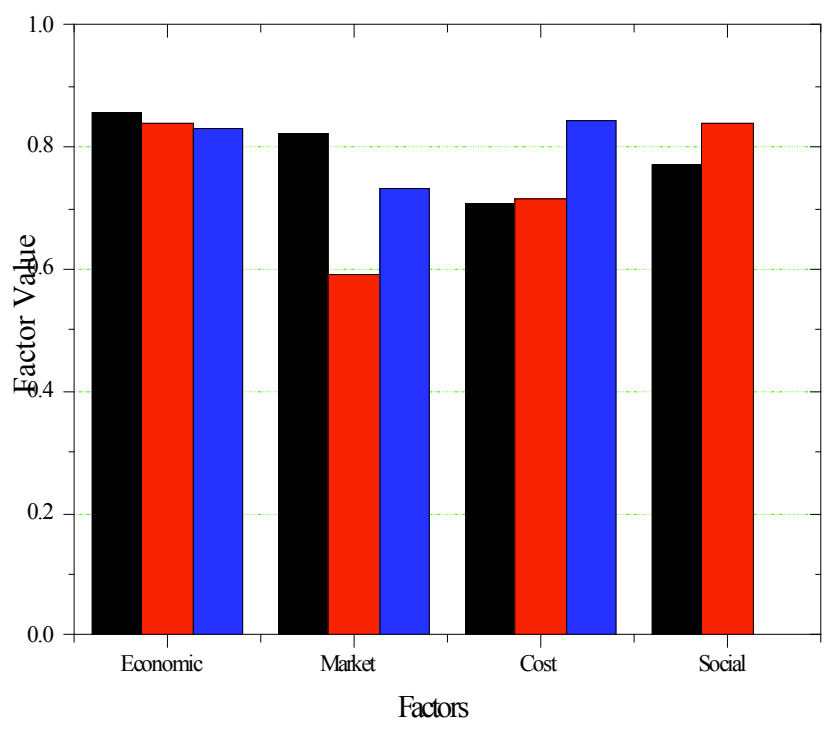

Fig. (1). Final results of factors of 11 factors.

(X1 and X2) in economic area are key influential factors. The factor X1 (gross domestic product) is the highest in the 11 factors, which means the GDP plays an important role on real estate price. As we know that real estate becomes pillar industry of national economy, it is consistent with the current situation. The other factors X2 (annual per capita disposable income of urban households) and X3 (annual per capita consumption expenditure of urban households) which describes disposable income and consumption expenditure of urban households are ranked third and fifth.

Market factors reflect the real estate market volatility which act on the real estate price in a direct way. Factor $\mathrm{X} 5$ (floor space of commercialized building sold) is the lowest in the 11 factors. Factor X4(real estate investment complete this year) is ranked sixth and factor 6(floor space complete) is ranked eighth.

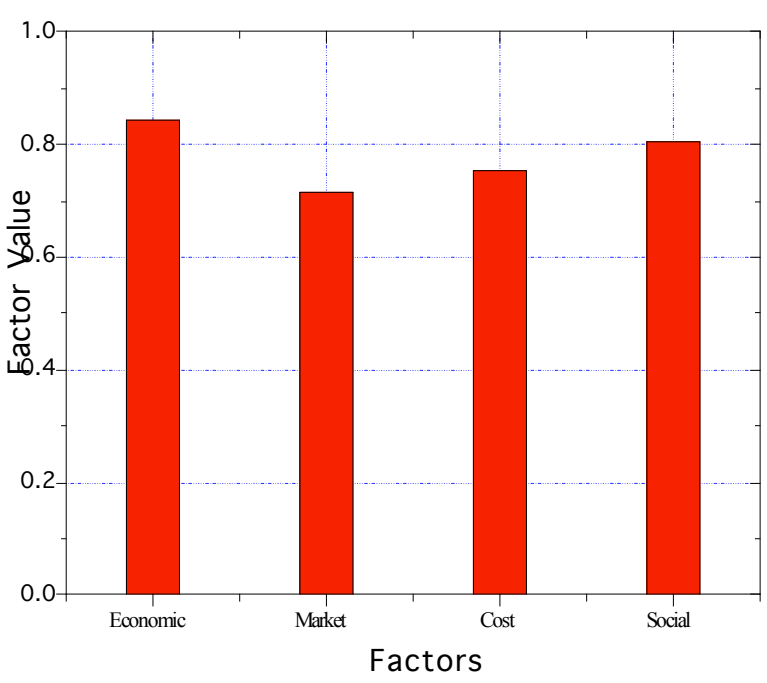

Fig. (2). Final results of four areas.

The grey relational coefficients of cost factors reflect the direct cost of real estate. In the three factors, X9(average wage of employed persons in construction) is the highest and also the second highest in the 11 factors, so it is also key influential factors. It shows that average wage of employed persons in construction is the important element in the real estate cost, which is consistent with the current situation that high wage of employed persons promote the real estate price. The result of factor X8(purchasing price index for building materials) is close to factor X7(average price of land purchased), and they are relatively ranked ninth and tenth.

The grey relational coefficients of social factors reflect the regional social situation which will influence real estate price. Factor X11 (per capita building space of urban household) is racked forth, which means the basic living condition of urban household, and it is also key influential factors. It shows that basic living space of urban household has impor- 
tant effects on real estate price. Factor 10(total population of a country or region) is racked seventh, which is a index reflecting the amount of people in a country or region.

\subsection{Results of the Four Areas}

The final results of economic factors, market factors, cost factors and social factors are summarized in Fig. (2). The economic factors is the highest $(0.8422)$, the second is the social factors $(0.8042)$, the third is the cost factors $(0.7533)$, and the last is the market factors (0.7158). It is found that all the four areas factors have relatively high relational coefficients (over 0.7), while the economic factors and social factors are higher (over 0.8), which means that economic factors impact on the real estate price most, second is market factors, third is cost factors and at last is market factors. This is in accordance with the results of 11 grey relational coefficients.

\section{CONCLUSION}

This study develops the influencing factors of real estate price, which include four areas: economic factors, market factors, cost factors and social factors. Through normalizing the selected eleven factors and calculating the grey coefficients of the eleven factors in the above four areas, the key influential factors are X1 (gross domestic product), X9 (average wage of employed persons in construction), X2 (annual per capita disposable income of urban households) and X11(per capita building space of urban household). In the four key influential factors, two are in economic areas, cost and social area has one separately. In the four areas, economic factors is the highest $(0.8422)$, the second is social factors $(0.8042)$, the third is cost factors $(0.7533)$, and the last is market factors $(0.7158)$.

However, this indicator is only proper for Dalian in China and current situations, with the economic development and the change of market, cost and social environment, the real estate price would also change, and the selected factors would also change. As a result, the final result of the research would be different to the description as discussed above.

\section{CONFLICT OF INTEREST}

The authors confirm that this article content has no conflict of interest.

\section{ACKNOWLEDGEMENTS}

This work is supported by the Central Universities Independent Research Fund, China (No.DC201502040302).

\section{REFERENCES}

[1] G. Jud, D. Winkler, and T. Daniel, "The announcement effect of an airport expansion on housing prices", Journal of Real Estate Finance and Economics, vol. 33, pp. 91-103, 2006.

[2] J. Gyourko, and J. Tracy, "The Structure of local public-finance and the quality-of-life in the united-states", Conference on Comparisons in Urban Economic Development in the United-States and WesternEurope, Italy, 1990, pp. 1950-1987.

[3] M. D. Lucia, A. Paez, V. J. Manuel, “Transportation infrastructure impacts on firm location: the effect of a new metro line in the suburbs of Madrid", Journal of Transport Geography, vol. 22, pp. 236-250, 2012.

[4] X., E. Xiaoqing, and T. Chen, "The effect of monetary policy on real estate price growth in China", Pacific-Basin Finance Journal, vol. 20, pp. 62-77, 2012.

[5] Y. Cheng, and X. Han, "Does large volatility help?-stochastic population forecasting technology in explaining real estate price process", Journal of Population Economics, vol. 26, pp. 323-356, 2013.

[6] Y. Pan, Y. Zhang, F. Li, and W. Luan, "Bubble and its burst: a double-chaotic model of dynamics and control in the estate market", Journal of Convergence Information Technology, vol. 7, pp. 349-359, 2012.

[7] N. Xie, and S. Liu, "A novel grey relational model based on grey number sequences”, Grey Systems: Theory and Application, vol. 1, pp. 117-128, 2011.

[8] S. Liu, "On perron-frobenius theorem of grey nonnegative matrix", The Journal of Grey System, vol. 1, pp. 157-166, 1989.

[9] E. Kose, "Grey relational analysis between energy consumption and economic growth", Grey Systems: Theory and Application, vol. 3, pp. 291-304, 2013.

[10] G. Liu, and A. M. Baniyounes, M. G. Rasua, M. T. O. Amanullah, and M. M. K. Khan, "General sustainability indicator of renewable energy system based on grey relational analysis", International Journal of Energy Research, vol. 37, pp. 1928-1936, 2013.

[11] W. Wang, Q. Cao, and X. Huang, "Identifying key influential factors of transforming regional science and education advantages into industrial advantages by grey relational analysis", The Journal of Grey System, vol. 25, pp. 63-75, 2013.

[12] J. Zhu, "Self-adaptation evolution method in real time dynamics decision-making system based on grey close relationship", Grey Systems: Theory and Application, vol. 3, pp. 276-290, 2013.

[13] H. Liu, W. Wang, Q. Zhang, and Y. Cai, "Knowledge integration of cluster networks based on grey relational analysis knowledge similarities", The Journal of Grey System, vol. 25, pp. 12-23, 2013.

Received: June 10, 2015

Revised: July 29, 2015

Accepted: August 15, 2015

(C) Jiang and Gao; Licensee Bentham Open.

This is an open access article licensed under the terms of the Creative Commons Attribution Non-Commercial License (http://creativecommons.org/licenses/by-nc/3.0/) which permits unrestricted, non-commercial use, distribution and reproduction in any medium, provided the work is properly cited. 